\title{
THE MEASUREMENT ACCURACY AND MEASUREMENT CHARACTERISTICS OF GREEN LIDAR DRONE
}

\author{
K. Mano ${ }^{1, *}$, K. Sakai ${ }^{1}$, K. Tachibana ${ }^{1}$, K. Sakita ${ }^{2}$, S. Nishiyama ${ }^{2}$ \\ ${ }^{1}$ PASCO CORPRATION, Japan - (koonua2121, kioauk2610, kainka9209)@ pasco.co.jp \\ ${ }^{2}$ Graduate school of environmental and life science, Okayama University, Okayama, Japan - \\ (pq1i4u6h@s.okayama-u.ac.jp, nishiyama.satoshi@okayama-u.ac.jp)
}

KEY WORDS: Green LiDAR, Drone, Point Cloud, Accuracy, Measurement Characteristics

\begin{abstract}
:
The aim of this study is to confirm the measurement accuracy and measurement characteristics of Green LiDAR Drone. In Japan, due to recent climate change, the frequency of heavy rainfall has been increasing, and more floods than estimated are occurring every year. Infrastructures that can safely drain the flood are river channel and river levee. Their role is becoming increasingly important. To reduce river disasters and manage disaster risk areas, river management administrations of Japan must understand the state of river channel and river levees. In order to fully identify risk area of disaster, it is considered using Green LiDAR Drone in Japanese river management. From these backgrounds, it is necessary to clarify the measurement accuracy and measurement characteristics of Green LiDAR Drone. Therefore, in this study, we confirmed the theoretical basic performance assumed from the device performance. Also, we conducted experimental measurements on flat ground area, river area, and coast area. Through verification of experimental measurements, we confirmed the positional accuracy, bathymetric capabilities of water area, and measurement characteristics of point cloud obtained by Green LiDAR Drone. As the result, it was confirmed the point cloud acquired by Green LiDAR Drone could understand not only the riverbed or coasts topography but also the structures of rivers and coasts, and could be used as basic information for maintenance and construction.
\end{abstract}

\section{INTRODUCTION}

In Japan, due to recent climate change, the frequency of heavy rainfall has been increasing, and more floods than estimated are occurring every year. Infrastructures that can safely drain the flood are river channel and river levee. Their role is becoming increasingly important. Therefore, in river management, it is necessary to accurately grasp the places with disaster risk in the river channels and river levees and take appropriate measures. To identify the locations of disaster risk, cross-section surveys and visual inspections have been carried out in Japan. The crosssection survey measures the height and cross-section shape of the river channel and levee at regular intervals such as $200 \mathrm{~m}$. In the visual inspection, after weeding the river levee, the topography and deformation of river channel and river levee are visually checked, and the length and depth are measured with a tape measure. However, it is difficult for cross-section surveys to grasp the disaster risk between survey lines, and it is difficult for visual inspection to properly digitize and accumulate river shapes and conditions.

To fully identify risk area of disaster, Airborne Laser Bathymetry (ALB), which can continuously measure river channels in three dimensions, is used (Hilldale et al. 2008), (Maas et al. 2019), (Straatsma et al. 2010) and (Yamaguchi et al. 2018). ALB performs laser measurement on airplane or helicopter flying at speeds over $110 \mathrm{~km} /$ hour. The density of point cloud acquired by ALB is about a few points at $1 \mathrm{~m}$ square. Such density of point cloud can reproduce natural topography of river channel but does not have enough point density to capture the shape of artificial river structures such as revetment, shoring and wave-dissipating blocks. In addition, ALB using airplane or helicopter has issue in terms of the cost in measuring a narrow area.

In recent years, Green LiDAR Drone, which is an unmanned aerial vehicle, has appeared. This LiDAR System can fly at slow speed of less than $20 \mathrm{~km} /$ hour from a flight altitude below $150 \mathrm{~m}$. It is possible to acquire high density point of several hundred points at $1 \mathrm{~m}$ square. It is expected the high-density point cloud acquired by Green LiDAR Drone can capture not only topography but also the shape of the river artificial structures and infrastructures. In addition, it is expected that Green LiDAR Drone can be obtained at a low cost in a narrow range. There are several existing studies that have validated the accuracy of lowdensity point cloud of a few points / $\mathrm{m}^{2}$ generated by ALB or Green LiDAR profiler Drone (Mandlburger et al. 2015) and (Mandlburger et al. 2016). However, few existing studies have verified the accuracy of high-density point cloud generated by Green LiDAR Drone.

In this study, we clarified the measurement accuracy and measurement characteristics of Green LiDAR Drone. Specifically, we confirmed the theoretical basic performance assumed from the device performance. We conducted experimental measurements on flat ground area, river area, and coast area. Through verification of experimental measurements, we confirmed the positional accuracy, bathymetric capabilities of water area, and measurement characteristics of point cloud obtained by Green LiDAR Drone.

\footnotetext{
* Corresponding author
} 


\section{GREEN LIDAR DRONE}

\subsection{Overview}

The Green LiDAR Drone uses a drone as a platform and mounts on a laser scanner that uses green laser wavelength, which has less attenuation through water than the near infrared wavelength (Mandlburger et al. 2015). The mechanism of measurement system is to irradiate the laser beam to the ground, observe the distance from the round-trip time of the laser beam that is reflected from the measurement target. And it observes Global Navigation Satellite System (GNSS) data and Inertial Measurement Unit (IMU) data at same time. From analysing these observation data, a point cloud is generated. In the water area, one part of the green laser irradiation from the drone is reflected on the water surface, and the other passes through the water surface is reflected on the water bottom. In laser measurement of the water area, point cloud generation is performed by taking effect of refraction into consideration. From these data analysis, it becomes possible to create a threedimensional point cloud in which land and water bottom are continuously connected.

\subsection{Green LiDAR Drone System}

In this study, we used TDOT GREEN as Green LiDAR Drone. (Amuse Oneself Inc., 2020). Figure 1 shows the external appearance of this device, Table 1 shows the device specifications, and the main features are shown below. The number of measurement points is 30,000 points / second. This Green LiDAR Drone, which can fly at a speed of several meters per second, can acquire a high-density laser point cloud of 100 points $/ \mathrm{m}^{2}$ or more. The footprint is approximately $50 \mathrm{~mm}$ at a flight altitude of $50 \mathrm{~m}$, which is smaller than that of aerial LiDAR survey. The laser scanner weight is $2.6 \mathrm{~kg}$ and is designed to be compact and lightweight. By mounted on the DJI Matrice 600 Pro (DJI Inc., 2020), a flight time of up to 22 minutes is possible. TDOTGREEN has an eye-safe function. It has a mechanism that reduces the laser output at an altitude above ground of $40 \mathrm{~m}$ (Nominal Ocular Hazard Distance: NOHD). Therefore, the flight altitude of this system is more than $40 \mathrm{~m}$.

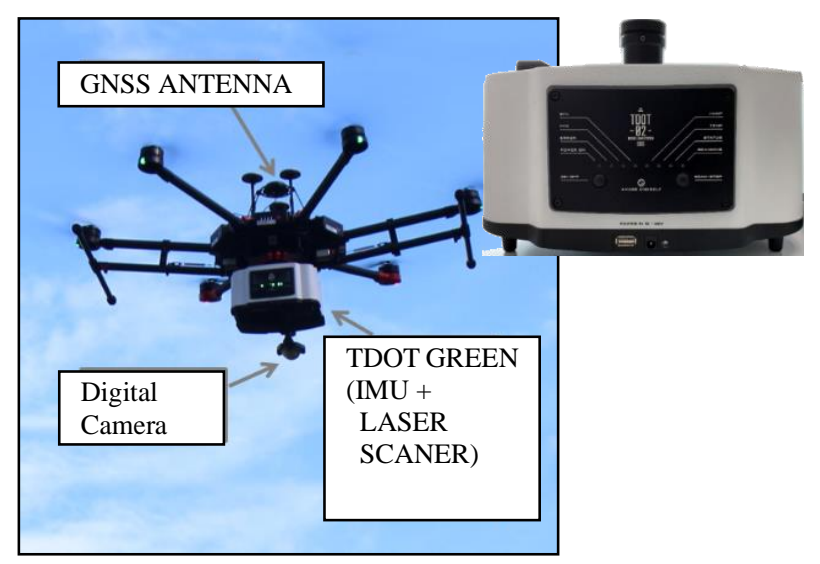

Figure 1. External appearance of TDOTGREEN

\subsection{Theoretical Measurement Accuracy}

The measurement accuracy of TDOT GREEN is expressed from theoretical equation (Mano et al. 2018). Theoretical measurement accuracy was estimated from equation (1) to (9) by using the specification (catalog spec.) of Table 1. The position error of

\begin{tabular}{|l|c|}
\hline Size & W260mm $\times$ D220mm $\times$ H150mm \\
Weight & $2.6 \mathrm{~kg}$ \\
Laser Range & $158 \mathrm{~m}:$ intensity $10 \%$ \\
Measurement Rate & $300 \mathrm{~m}:$ intensity $60 \%$ \\
FOV & 30,000 points $/$ second \\
Measurement width & $90^{\circ}$ \\
Laser Wavelength & $50 \mathrm{~m} @$ flight altitude $50 \mathrm{~m}$ \\
Laser Beam Divergence & $512 \mathrm{~nm}$ \\
Laser Footprint & 1 mrad \\
Laser Accuracy & $50 \mathrm{~mm} @$ altitude $50 \mathrm{~m}$ \\
& $\pm 15 \mathrm{~mm}:$ intensity $10 \%$ \\
GNSS/ IMU Trajectory & $\pm 5 \mathrm{~mm}:$ intensity $60 \%$ \\
Accuracy & $\begin{array}{c}\text { Horizontal accuracy } 10 \mathrm{~mm} * \\
\text { Vertical Accuracy } 20 \mathrm{~mm} *\end{array}$ \\
IMU Angle Accuracy & $*$ Under good GNSS reception \\
& condition \\
Yaw $\pm 0.02^{\circ}$
\end{tabular}

Table 1. The specification of TDOT GREEN

GNSS measurement was used GNSS/ IMU trajectory accuracy under good GNSS reception condition. Error of laser scanner was used laser accuracy of intensity $10 \%$. Error due to laser footprint was estimated from laser beam divergence. Error of laser angle measurement was used IMU angle accuracy. From these value, error of entire point cloud was estimated, and was illustrated at Figure 2. It was confirmed that the theoretical measurement accuracy of TDOT GREEN was approximately $40 \mathrm{~mm}$ at flight altitude of $50 \mathrm{~m}$.

$$
\begin{aligned}
E_{x p} & =(\sin (\varphi+\Delta \varphi)-\sin (\varphi)) \times L \\
E_{z p} & =(\cos (\varphi)-\cos (\varphi+\Delta \varphi)) \times L \\
E_{y r} & =(\sin (\omega+\Delta \omega)-\sin (\omega)) \times L \\
E_{z r} & =(\cos (\omega)-\cos (\omega+\Delta \omega)) \times L \\
E_{x h} & =(\sin (\kappa+\Delta \kappa)-\sin (\kappa)) \times L \\
E_{y h} & =(\cos (\kappa)-\cos (\kappa+\Delta \kappa)) \times L \\
E_{I M U} & =\sqrt{E_{x p}^{2}+E_{z p}^{2}+E_{y r}^{2}+E_{z r}^{2}+E_{x h}^{2}+E_{y h}^{2}} \\
E_{S}^{2} & =E_{l d}^{2}+E_{l a}^{2}+E_{f p}^{2} \\
E_{x y z} & =\sqrt{E_{G N S S}^{2}+E_{I M U}^{2}+E_{S}^{2}+E_{C}^{2}}
\end{aligned}
$$

where $E_{x p}$ : Error in the direction of flight due to pitch tilt, $E_{z p}$ : Vertical error due to pitch tilt,

$E_{y r}$ : Error in the right angle of flight due to tilt of roll,

$E_{z r}$ : Vertical error due to tilt of the roll,

$E_{x h}$ : Flight direction error due to heading tilt,

$E_{y h}$ : Flight perpendicular error due to heading tilt, $\varphi$ : Pitch angle,

$\Delta \varphi$ : IMU measurement error of pitch angle,

$\omega$ : Roll angle,

$\Delta \omega$ : IMU measurement error of roll angle,

$\kappa$ : Heading angle,

$\Delta \kappa$ : IMU measurement error of heading angle,

$L$ : Measuring distance of the laser,

$E_{I M U}$ : IMU measurement error of angle,

$E_{x y z}$ : Error of entire point cloud,

$E_{G N S S}$ : Position error of GNSS measurement,

$E_{S}$ : Error of laser scanner,

$E_{f p}$ : Error due to laser footprint,

$E_{l d}$ : Error of Laser distance, 
$E_{l a}$ : Error of Laser angle measurement,

$E_{c}$ : Error of Boresight calibration,

Ela: Error of laser angle measurement.

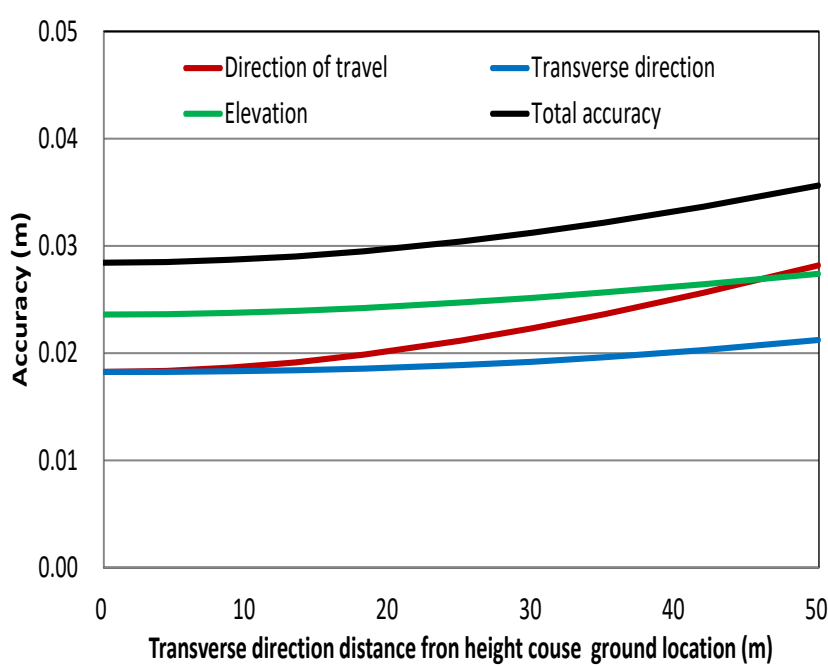

Figure2. Estimated Measurement Accuracy at flight altitude of $50 \mathrm{~m}$

\section{EXPERIMENTAL MEASUREMENT}

To complete our study, experimental measurements were performed at three locations consisting of flat ground area, river area, and coast area.

\subsection{Flat Ground Area}

In the flat ground area, Green LiDAR Drone measurement was performed at flight altitudes of $50 \mathrm{~m}$ on a flat ground which was approximately $200 \mathrm{~m} \times 150 \mathrm{~m}$. To confirm the positional accuracy, we set nine signalized points consisted of 5 check points and 4 Ground Control Point (GCP)'s . The position of the signalized points was obtained by ground survey with Total Station from existing reference points.

\subsection{River Area}

Green LiDAR Drone measurements were performed in river area to understand topographical reproducibility of river channel, river levees, and river artificial structures such as river weir. This measurement was performed on a river at a flight altitude of 40 $\mathrm{m}$ and a flight speed of $2.5 \mathrm{~m} / \mathrm{second}$. In a part of this area, crosssection survey using Total Station was conducted.

\subsection{Coast Area}

To understand the shape reproducibility of infrastructures, Green LiDAR Drone measurement was performed on around breakwater at a flight altitude of $40 \mathrm{~m}$ and a flight speed of $2.5 \mathrm{~m}$ / second. These measurement specifications could acquire point cloud with point density of 100 points $/ \mathrm{m}^{2}$ or more.

\section{VERIFICATION}

\subsection{Positional Accuracy in Flat Ground Area}

From comparison coordinate values of GCPs by Total Station and point cloud, it was confirmed systematic error. To reduce systematic error, shift correction method was used as the position correction. As shift correction amount, the positional difference between the GCPs obtained by Total Station and the GCPs read from the point cloud was used.

In order to confirm positional accuracy, the point cloud and the coordinate values of check points acquired by Total Station were compared. Figure 3 shows the verification results. The Root Mean Squared Error (RMSE) of vertical position shows $60 \mathrm{~mm}$ or less at the unadjusted plane position, and the maximum difference was $70 \mathrm{~mm}$ or less at both horizontal position and vertical position. The vertical position accuracy after adjustment was greatly improved with a maximum range of $30 \mathrm{~mm}$ or less. However, the horizontal position accuracy resulted in a slight improvement, but not a great improvement. We thought the cause of this result was assumed to be a point cloud reading error deriving from measurement point intervals of about $100 \mathrm{~mm}$. Concerning vertical results, it was confirmed that after position correction, results were almost equivalent to the estimated measurement accuracy by equation (1) to (9) .

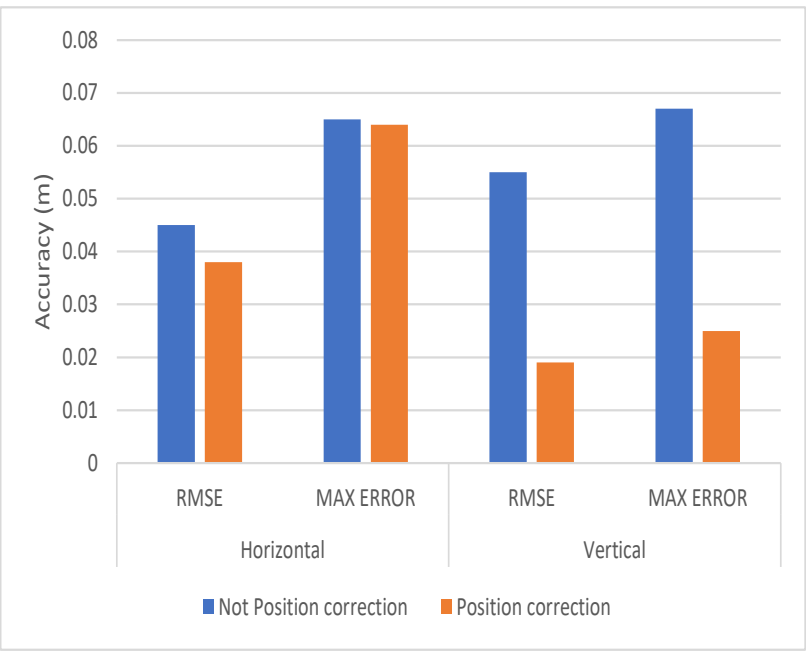

Figure3. Verification Results of positional Accuracy

\subsection{Positional Accuracy and Reproducibility in River Area}

To confirm the positional accuracy of the water area and the reproducibility of the cross-sectional shape, we compared point cloud of TDOT GREEN with the results of cross-section survey by Total Station survey. Table 2 shows the comparison results of the cross-section survey and the point cloud. Also Figure 4 shows the cross-sectional view of the Total Station survey and point cloud. The vertical difference from the cross-section survey and point cloud was below RMSE $160 \mathrm{~mm}$ for both water area and land area, and the maximum difference was about $400 \mathrm{~mm}$. It was presumed that this was due to the stones with a diameter of several tens of centimetres existing in $r$ river. From Figure 4, it could be confirmed that the maximum depth can be $3.2 \mathrm{~m}$ in this area's measurement. Water depths below $3.2 \mathrm{~m}$ are missing. Except for missing area, it was confirmed that the shape of crosssectional by the point cloud was almost the same as the result of the cross-section survey, although there were some differences in large stones and steep slopes.

\begin{tabular}{|l|c|c|}
\hline & Land area & Water area \\
\hline Number of points & 238 & 30 \\
Average error $(\mathrm{mm})$ & 14 & 52 \\
Maximum error(mm) & 333 & 386 \\
standard variation(mm) & 109 & 160 \\
RMSE $(\mathrm{mm})$ & 109 & 166 \\
\hline
\end{tabular}

Table 1. Comparison of Cross-section Survey and Point Cloud 


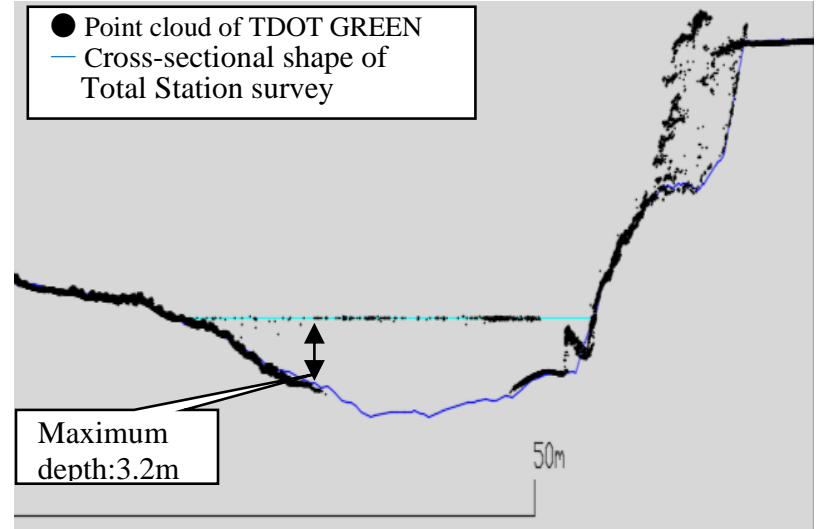

Figure4. Cross-sectional View of Total Station Result and the Point Cloud

\subsection{Infrastructures Reproducibility in River and Coast Area}

Figure 5 shows a bird's-eye view and cross-section generated from point cloud obtained around the river weir. Figure 6 shows an elevation map, a bird's-eye view and cross-sectional view of the point cloud around breakwater. From Figure 5, it was possible to confirm the shape of the weir s main structure, gate, gate post, and block of groundsill from the high-density point cloud of 100 points $/ \mathrm{m}^{2}$. It could also be identified a situation where some blocks of the groundsill have collapsed. Elevation Map of Figure 6 can be confirmed the continuous topography which ware shallower than $6 \mathrm{~m}$ depth of water area and land area. And the bird's-eye view and cross-section of Figure 6 shows how the shape of the block that makes up the breakwater was confirmed.
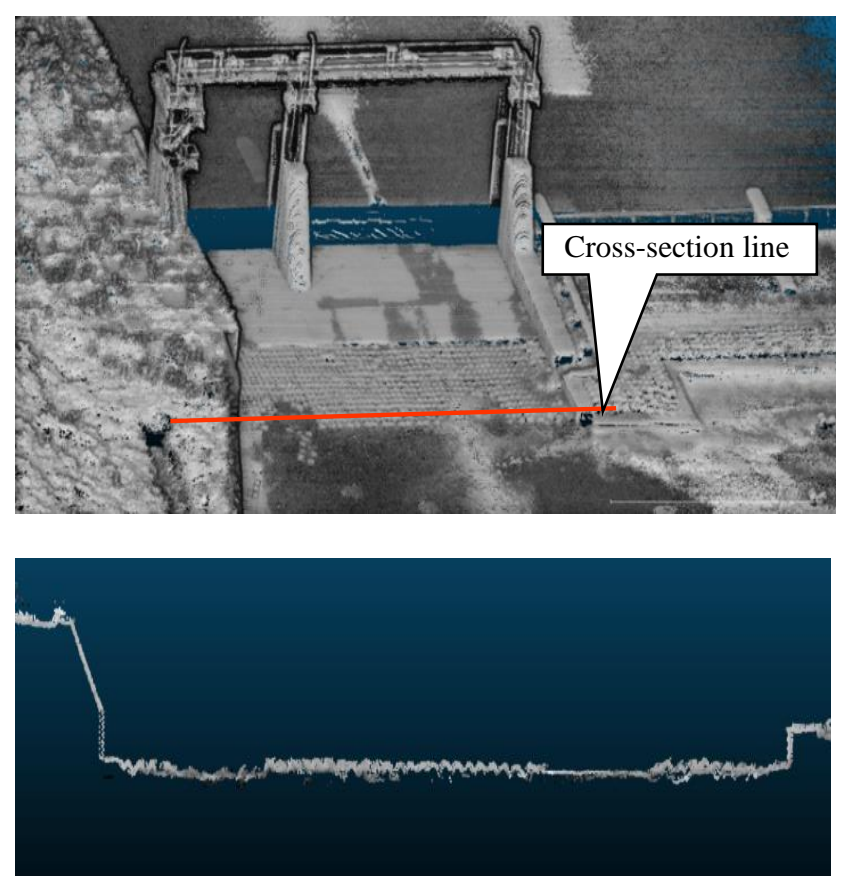

Figure5. Bird's-eye view and Cross-section Around River Weir It was also possible to understand the situation where a part of the breakwater was tilted. It was difficult for echo sounding to identify the terrain where the water depth is less than $2 \mathrm{~m}$, because it was not possible for the ship to be navigated to the point. From these results, it was confirmed that not only the topography of land, riverbed, and coasts but also the structures of rivers and coasts could be identified in detail and could be used as basic information for maintenance and construction.
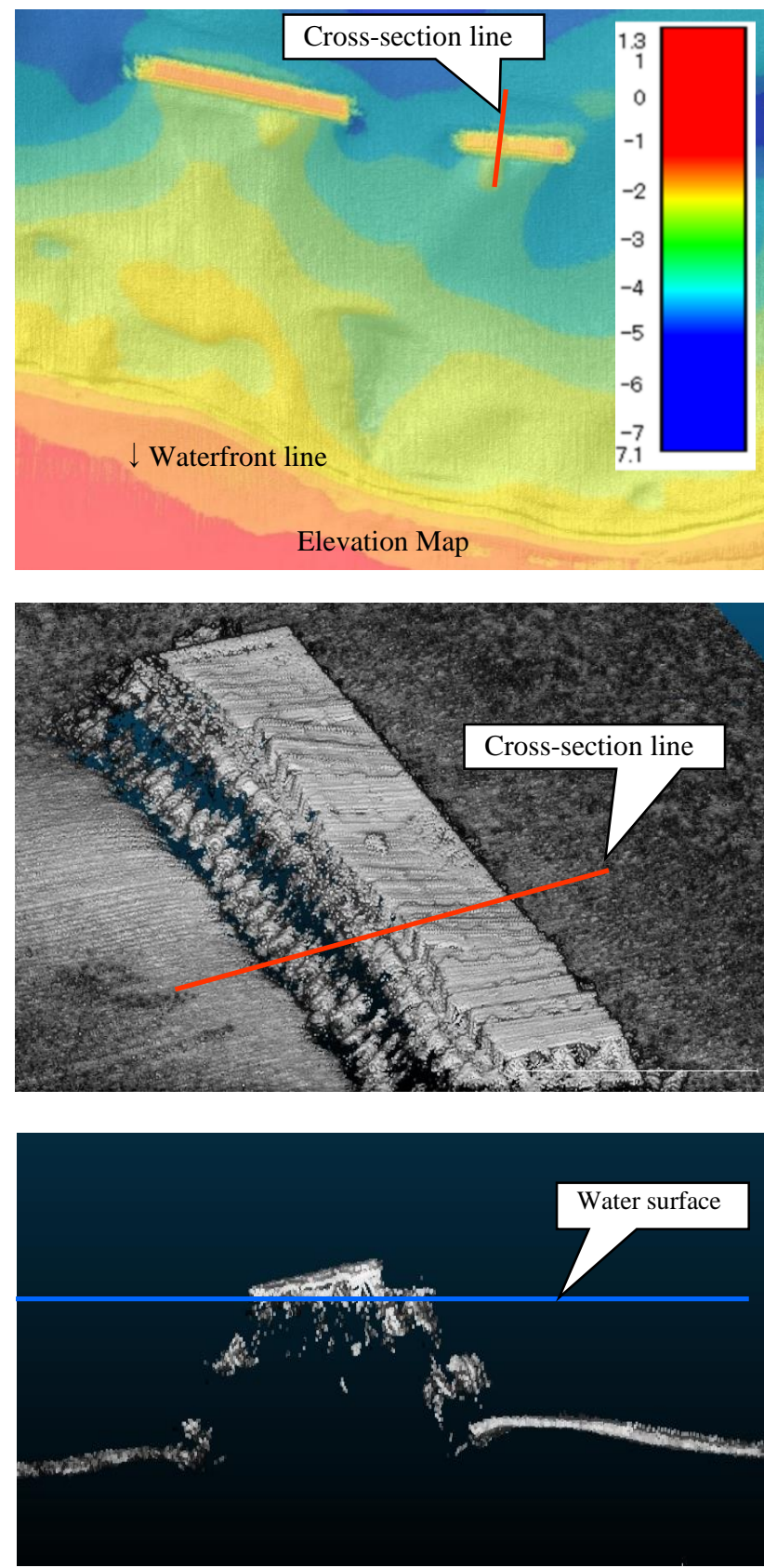

Figure6. Elevation Map, Bird's-eye view and Cross-section Around Breakwater

\section{CONCLUSTION}

Through verification of experimental measurements, the following knowledge was obtained about the measurement accuracy and measurement characteristics of Green LiDAR Drone.

The following shows the measurement accuracy of TDOT GREEN

- $\quad$ Positional accuracy of TDOT GREEN showed $60 \mathrm{~mm}$ or less at the unadjusted position correction. And results of adjusted position correction were almost equivalent to the theoretical measurement accuracy in ground area.

- In river area, it could be confirmed that the maximum depth can be $3.2 \mathrm{~m}$ in this experimental measurement of river area which is good water condition area. 
- In coast area, it could be confirmed that the maximum depth can be $6 \mathrm{~m}$ in this experimental measurement of coast area which is good water condition area. And it could be confirmed that continuous topography which ware shallower than $6 \mathrm{~m}$ depth of water area and land area.

- The point cloud acquired by TDOT GREEN could reproduce the river cross-sectional shape. The reproducibility was almost the same as the cross section obtained by ground survey.

- Green LiDAR Drone can acquire the high-density point cloud, which can be confirmed the shape of block of the weir structure and the breakwater and could also capture the state of the collapsed block.

- It was possible to measure the topography up to the depth of $3.2 \mathrm{~m}$, which was difficult for the acoustic sounding by the ship and to obtain the three-dimensional data in which the land part and the water part were continuously connected.

And the following shows the measurement characteristics of Green LiDAR Drone

- The point cloud acquired by Green LiDAR Drone can identify not only the riverbed or coasts topography but also the artificial structures and infrastructures of rivers and coasts in detail.

- The dense point cloud acquired by Green LiDAR Drone can be used as basic information for maintenance and construction of river management and coast management.

The problem of Green LiDAR was that the bathymetry capacity varies depending on water condition such as the water quality, the condition of water surface, and the condition of the riverbed or seabed (Birkebak et al. 2108) and (Clescerl et al. 1999). Therefore, in future, the number of measurement verifications should be increased in order to understand the effect of bathymetry capacity on water condition. The understanding of the applicable range of Green LiDAR Drone is expected to contribute to advanced and efficient river management and coast management.

\section{REFERENCES}

AMUSE ONSELF Inc., 2020, TDOT GREEN, https://amuseoneself.com/service/tdotgreen (20 April 2020).

Birkebak, M., Eren, F., Pe'eri, S.;Weston, N.,2018: The Effect of Surface Waves on Airborne Lidar Bathymetry (ALB) Measurement Uncertainties, Remote Sens. 10, 453.

Clescerl, L. S., Greenberg, A. E., Eaton, A. D., 1999: Standard methods for the examination of water and wastewater, 2130 turbidity (20th ed.). Washington, DC: American Public Health Association.

DJI Technology Inc., 2020, Mattice 600 Pro, https://www.dji.com/jp/matrice600-pro (20 April 2020).

Hilldale, R., Raff, D., 2008: Assessing the ability of airborne LiDAR to map river bathymetry. Earth Surf. Process. Landforms, 33, 773-783.

Kinzel, P.J., Legleiter, C.J., Nelson, J.M., 2013: Mapping River BathymetryWith a Small Footprint Green LiDAR, Applications and Challenges. JAWRA J. Am. Water Resour. Assoc, 49, 183204.
Maas, H.G.; Mader, D., Richter, K., Westfeld, P., 2019: Improvements in lidar bathymetry data analysis. ISPRS Int. Arch. Photogramm. Remote Sens. Spat. Inf. Sci., XLII-2/W10, 113-117.

Mandlburger, G.; Hauer, C., Wieser, M., Pfeifer, N., 2015: Topobathymetric LiDAR for monitoring river morphodynamics and instream habitats-A case study at the Pielach River. Remote Sens., 7, 6160-6195.

Mandlburger, G., M. Pfennigbauer b, M. Wieser a, U. Riegl b, N. Pfeifer a., 2016: EVALUATION OF A NOVEL UAV-BORNE TOPO-BATHYMETRIC LASER PROFILER, Remote Sensing and Spatial Information Sciences, Volume XLI-B1, pp.933-939

Mano, K., Sakai, K., Tachibana K., Tomii, T., Nishiyama, S.,2018: Study on Calibration for UAV LiDAR, Journal of applied survey technology, 30, 63-74.

Straatsma, M. W., Baptist, M. J., 2008: Floodplain roughness parametrization using airborne laser scanning and spectral remote sensing, Remote Sensing of Enviro\ment, 112, 10621080.

Yamaguchi, K., Yoshida, K., Maeno, S., Mano, K., Akoh, R., Nishiyama, S., 2018: Study on the Improvement Effect of Application of Alb for River Channel Topography on River-Bed Variation Analysis. Journal of Japan Society of Civil Engineers, Ser. A2 (Applied Mechanics (AM)), vol. 74, issue 2, pp. I_465I 474 .

Revised May 2020 